\title{
DETALHAMENTO DAS CLASSES SOLOS DA BACIA HIDROGRÁFICA DO RIACHO DO TIGRE
}

\section{SOIL CLASSES DETALLIING OF HYDROGRAFIC BASIN: RIACHO DO TIGRE}

\author{
Lima, S. M.; Souza, J. O. P. \\ stephanie_m.l@hotmail.com;
}

\begin{abstract}
Resumo
Este trabalho teve por objetivo contribuir para o aumento na precisão do mapeamento de solos com o detalhamento de escala. A área de estudo corresponde a Bacia do Riacho Tigre que está localizada no município de São João do Tigre-PB. Para o desenvolvimento da metodologia foi elaborado e analisados mapas temáticos sobre os aspectos físicos da bacia, utilizando o software Arcmap 10.3. Inicialmente foi criado o mapa das classes de solos predominantes na Bacia, com utilização de dados da IDEME-PB. Por tanto foi constatado 3 classes de solos e 9 unidades de mapeamento. Na sequência foi definido o Modelo Digital de Elevação da área a partir de imagens SRTM, do Brasil em Relevo. A partir da analise do mapeamento das classes de solos da Bacia Riacho do Jucurutu que ocupa uma grande área do município de São João do Tigre, constatou-se três classes de solos, que são: Neossolos Litolicos, Neossolo Regolitico e Luvissolo.
\end{abstract}

\begin{abstract}
The objective this present work is to contribute for digital mapping concern. This Studying place is Jucurutu River Catchment in São João do Tigre - PB. For the development of the methodology followed was a execution's sequence of thematic maps on the physical aspects of the basin, using ArcMap 10.3 software. Initially created the soil's types maps prevalent in the basin, using data from IDEME-PB. Therefore featured in three soil and 9 classes mapping units. Following it is defined the Digital Elevation Model of the area from SRTM images, Brazil in relief. From the Creek's Basin soil classes mapping, that has a great area of São João do Tigre city and found three classes of soil, are they Litholic Neosols, Entisol and Luvisol.
\end{abstract}

Keywords: mapping, classes, dryland

\section{INTRODUÇÃO}

O desenvolvimento de novas técnicas de sensoriamento remoto e de cartografia vem crescendo ao longo das últimas décadas, devido à necessidade de se obter dados de forma mais eficiente, em termos de precisão e curto tempo, do meio ambiente. No que se refere Pedologia a cartografia é imprescindível para um levantamento de solos preciso e detalhado, ainda que, seja necessário que se tenha conhecimento prévio dos fatores e processos condicionantes do sistema pedológico.

No Brasil, por exemplo, há poucos mapeamentos pedológicos em grande escala , devido, entre outras coisas, à falta de investimentos na cartografia pedológica, embora seja claro que os mapeamentos permitem um melhor planejamento e manejo dos solos. Uma vez que possibilita a análise da distribuição espacial dos solos e suas propriedades, incluindo a ação dos processos pedogenéticos ocorrentes, bem como permite avaliar seu potencial agrícola, geotécnico e ambiental (LEPSCH,2011). Dessa forma, tem-se como resultado a obtenção de informações especificas sobre 
a taxonomia dos solos, entretanto o nível de detalhamento dos mapas dependerá da ordem de escala em que estão sendo executados, os quais poderão ser definidos na seguinte ordem: semidetalhados (1:25000 a 1:50000), detalhados (1:5000 a 1:25000) e ultradetalhados (1:5000 ou maior).

As mais diversas metodologias e técnicas foram desenvolvidas a fim de refinar o mapeamento digital dos solos que são utilizadas para sistematizar informações a partir de um conjunto de dados existentes, assim auxiliando na extração de dados essencias para o estudo. Entre exemplos em destaque estão: a mineração de dados, árvores de decisão e arvores de classificação (BEHRENS et al., 2005). As RNA (redes neurais artificiais) vem sendo aplicadas com frequência na pedologia para identificação de propriedades hidráulicas dos solos. Assim como satélites como o Landsat ou QuickBird também são usados como forma de baratear os custos com o mapeamento, bem como novas tecnologias como os veículos aéreos não tripulados os quais podem fornecer imagens de alta resolução a baixo custo.

A identificação dos solos, também, pode ser feita a partir de uma análise dos tipos de catenas predominantes na área de estudo, que corresponderá a uma sucessão de solos que estão expostos a processos naturais ocorrentes nas encostas. Tendo como principal fator condicionante a declividade e da posição na encosta. Portanto, torna-se importante uma caracterização física do relevo a partir de técnicas que avaliem os atributos do terreno, a exemplo da elaboração de modelos digitais de elevação (MDE), que servirão para a compreensão das relações espaciais entre classes de solos e diferentes variáveis do relevo. Os atributos topográficos, também designados como variáveis morfométricas, são geralmente derivados do MDE por meio de métodos de interpolação. Estes atributos são comumente utilizados como variáveis auxiliares na predição espacial dos padrões solo-paisagem e contribuem para o aperfeiçoamento do mapeamento de classes e de propriedades do solo, como espessura de horizontes, elementos na solução do solo, textura, cor, umidade, entre outras (GESSLER et al, 2000).

Deste modo, o objetivo do presente análise visa corroborar a importância das informações morfométricas, especialmente a declividade, para o desmembramento das Unidades de Solos e consequentemente, para o detalhamento da distribuição espacial das classes de solos em ambiente semiárido, tendo como área analisada a Bacia Riacho do Tigre, no município de São João do Tigre semiárido paraibano. 


\section{METODOLOGIA}

A área de estudo corresponde a Bacia hidrográfica do Riacho do Tigre (Figura 01) que está localizada no município de São João do Tigre-PB, limitado geograficamente pelas coordenadas $08^{\circ} 04^{\prime} 45^{\prime \prime} \mathrm{S}$ e $36^{\circ} 50^{\prime}$ 52, possui uma área de 816,116 km² (IBGE- Instituto Brasileiro de Geografia e Estatística). Estando inserida no Planalto da Borborema, na Depressão Interplanáltica da Paraíba, com relevo predominantemente suave-ondulado. Ela faz parte da bacia do Rio Paraíba, apresentando cerca de $564 \mathrm{~km}^{2}$, com variação altimétrica de 500 até $1100 \mathrm{~m}$.

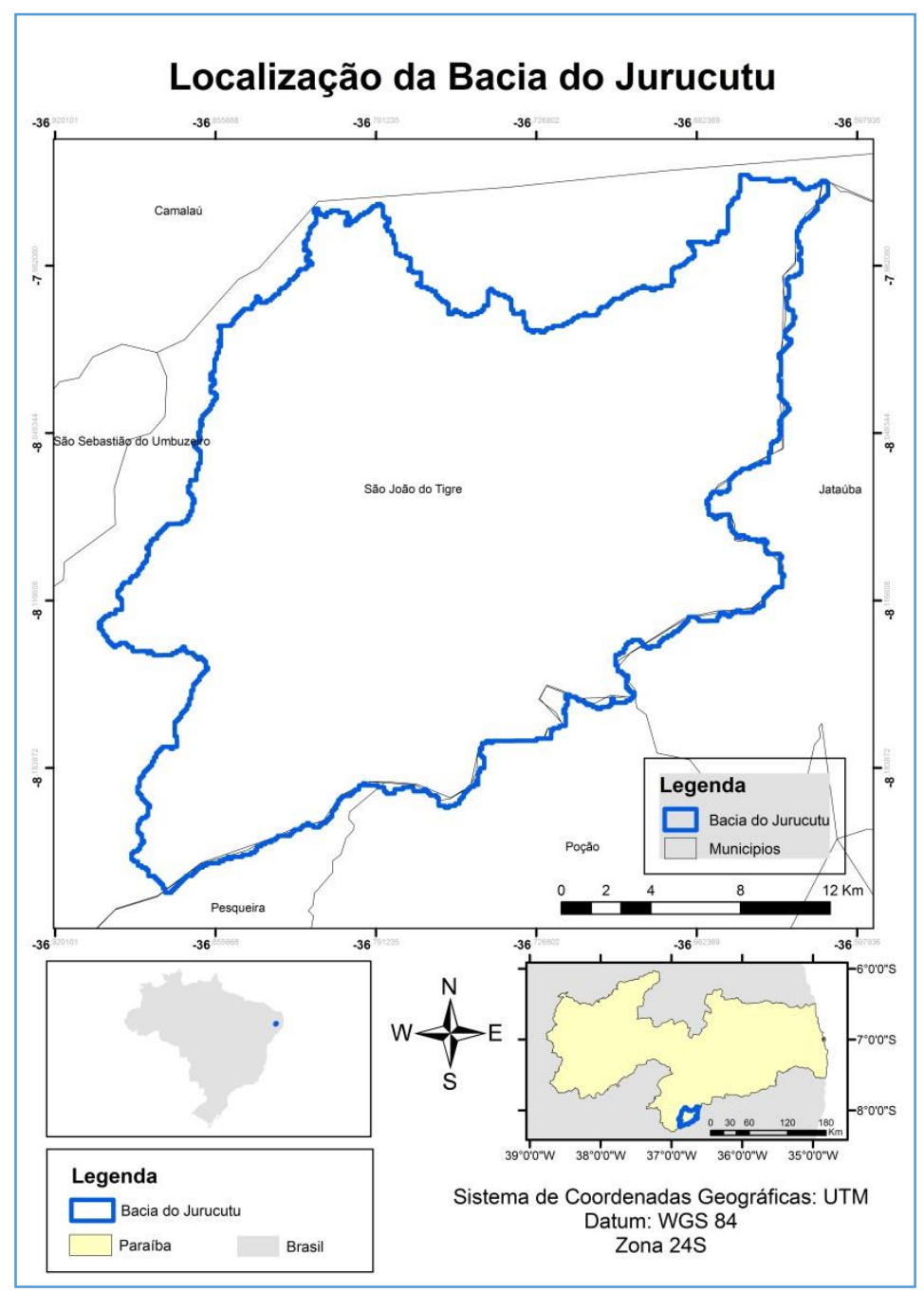

Figura 01. Mapa de Localização da Bacia do Riacho do Tigre. Fonte: Stéphanie Lima,2016

Para o desenvolvimento da metodologia foi elaborado mapas temáticos sobre os aspectos físicos da bacia utilizando o software Arcmap 10.3. Inicialmente foi criado o mapa das classes de solos predominantes na Bacia, com utilização de dados do IDEME-PB. Em que foi constatado 3 classes de solos e 9 unidades de mapeamento. Na sequência foi definido o Modelo Digital de Elevação da área a partir de imagens SRTM, do Brasil em Relevo. Com os dados de altitude resultantes do MDE, gerou-se o mapa Declividade (em porcentagem e em graus), visto a 
necessidade de obter informações sobre a distribuição espacial das classes de solos e suas unidades no relevo da Bacia. A partir das interações dos dados de declividade com o conhecimento das catenas comuns para a área foi possível o desmembramento das unidades de solo e o detalhamento da distribuição de solos para a bacia, bem como a identificação de afloramentos rochosos em áreas de maior declive, assim representados no mapa de declividade ( Figura 02).

\section{MAPA DE DECLIVIDADE EM PORCENTAGEM BACIA DO JUCURUTU}

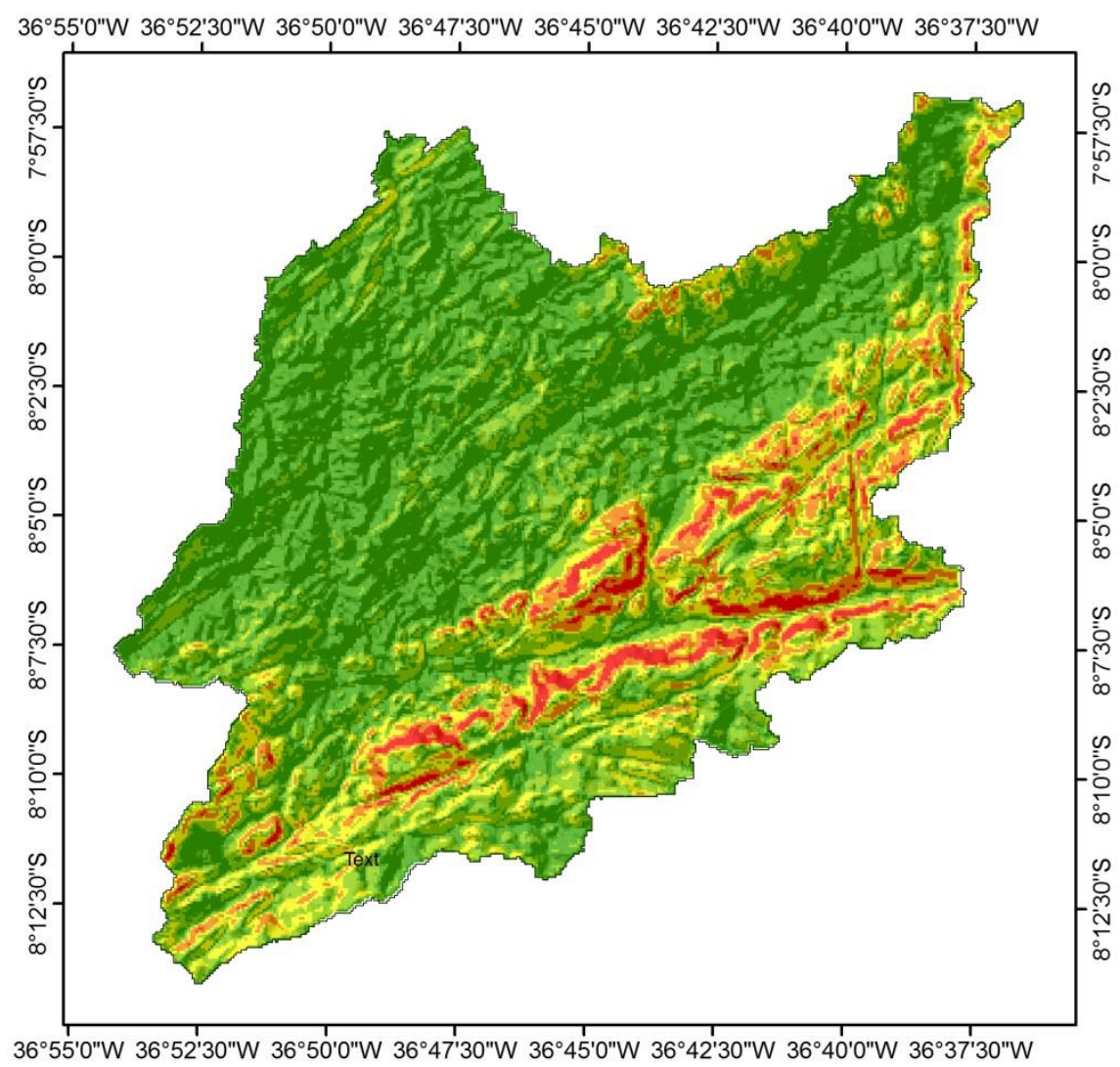

\section{Legenda}
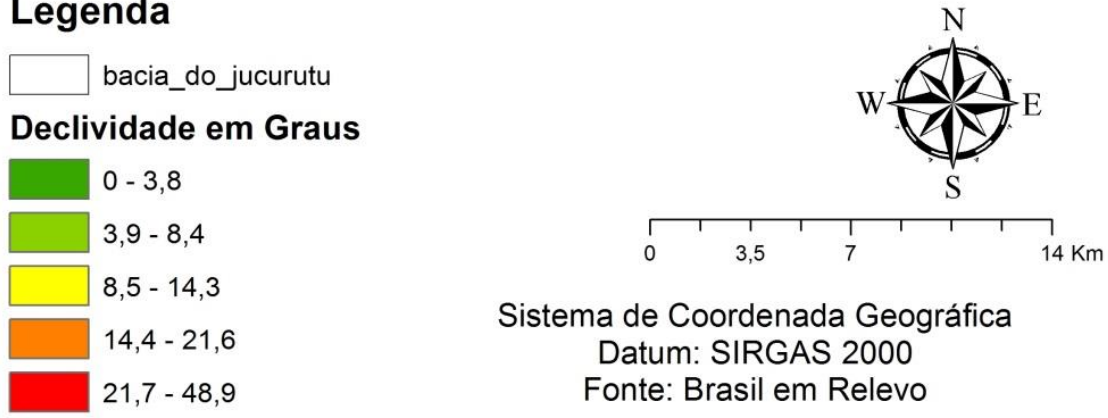

Sistema de Coordenada Geográfica

Datum: SIRGAS 2000

Fonte: Brasil em Relevo

Figura 02. Mapa de Declividade da Bacia do Riacho do Tigre. Fonte: Stéphanie Lima,2016

Portanto, o trabalho foi realizado pura e estritamente com ferramentas geotcnológicas a partir de informações secundárias e técnicas habilitadas por extensões do software, neste caso o 
ArcGis, do qual foram extraídos elementos ou novas informações para a construção de um levantamento de solos detalhado e contribuinte para caracterização das classes de solos da Bacia do Riacho do Tigre-PB. Com finalidade na criação de um banco de dados pedológicos da área correspondente.

\section{RESULTADOS E DISCUSSÃO}

A partir da análise do mapeamento das classes de solos da Bacia Riacho do Jucurutu que ocupa uma área de $564 \mathrm{~km}$ do município de São João do Tigre, constatou-se três classes de solos, que são: Neossolos Litolicos, Neossolo Regolitico e Luvissolo. Assim representado na figura 03.

\section{MAPA DE SOLOS DA BACIA RIACHO DO TIGRE}

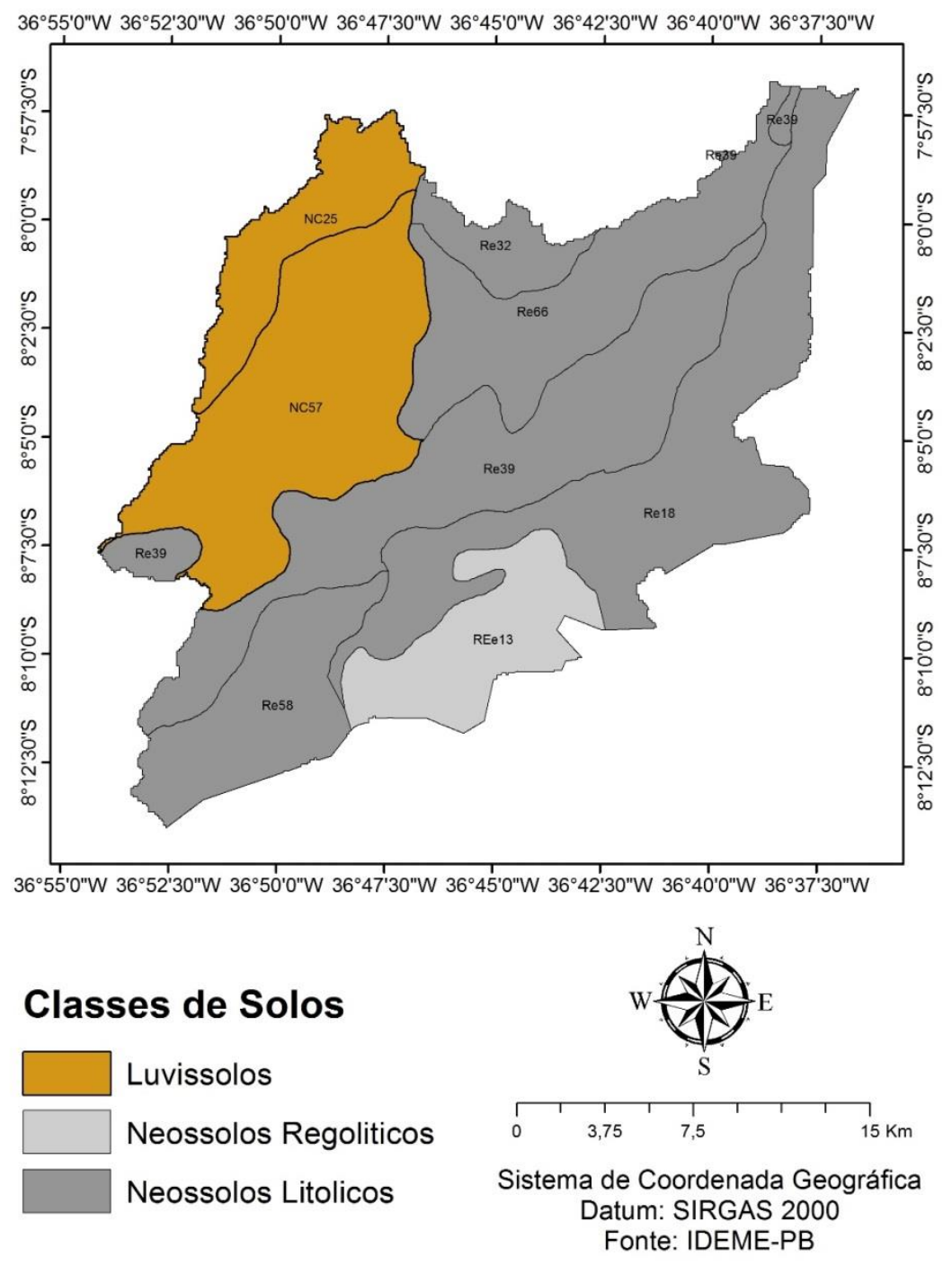

Figura03.Mapa de Solos da Bacia Hidrográfica Riacho do Tigre. Fonte: Stéphanie Lima, 2016 
Os luvissolos são solos pouco ou mediamente intemperizados, ricos em bases e com acumulação de argila no horizonte B(LEPSCH,2011). Esta classe de solo subdividi-se em duas classes, que são: Luvissolos Crômicos e Háplicos. Que são encontrados em catenas constituidas em pedimentos, comum onde o relevo é plano ou suavemente ondulado o que favorece o processo de bissialitização. A bissialitização é um processo ocorrente ao regime semi-árido, em vista da sua baixa drenagem (BARROS et al.).O Luvissolo Crômico se configura com um perfil pouco profundo ( não mais com $1 \mathrm{~m}$ profundidade de solo) a escassez de chuvas e as condições climáticas justificam a espessura pequena dos Luvissolos Cromicos. A falta de umidade inibi a decomposição das rochas e, consequentemente, o desenvolvimento de solos mais profundos.

Os Neossolos são solos com pouca ou nenhuma evidência de horizontes pedogenéticos subsuperficiais. Os Neossolos formam-se em materiais praticamente inertes, sem argilas extremamente resistentes ao intemperismo ( como areias de quartzo) ou estão tão pouco e recentemente expostos aos processos pedogenéticos que os horizontes diagnósticos típicos estão ausentes. Os Neossolos litólicos são distribuídos predominantemente em declives fortes de áreas com relevo em constante alteração. Configurando o solo raso e com presença de rocha e da frequente pedregosidade. Os Neossolos Regoliticos, apesar de não apresentarem rocha a pouca profundidade apresenta obstáculos pela propensão a erosão, semelhantes ás dos Litólicos ( LEPSCH,2011).

O mapeamento detalhado permitiu desmembrar as 9 unidades de mapeamento classificadas em: NC57 que corresponde a uma associação de Luvissolos e Neossolo Litolico localizados na parte do relevo suave ondulado. O Re39 e Re66 correspondem a uma associação de Neossolos Litolicos e Rochas situados em uma área em que o relevo se caracteriza forte ondulado e montanhoso substrato gnaisse e granito. O NC25 corresponde a uma associação de Luvissolos Vértico e Neossolos Litolicos constado em relevo suave ondulado. O Re32 constitui a associação de Neossolos Litolicos e Afloramento de Rochas encontrado em duas partes do relevo, ondulado e forte ondulado. REe13-Neossolos Regoliticos , Re18- Neossolos Litolicos e Re58- Neossolos Litolicos. Representado abaixo na Figura 04: 


\section{MAPA DE SOLOS DA BACIA RIACHO DO TIGRE}

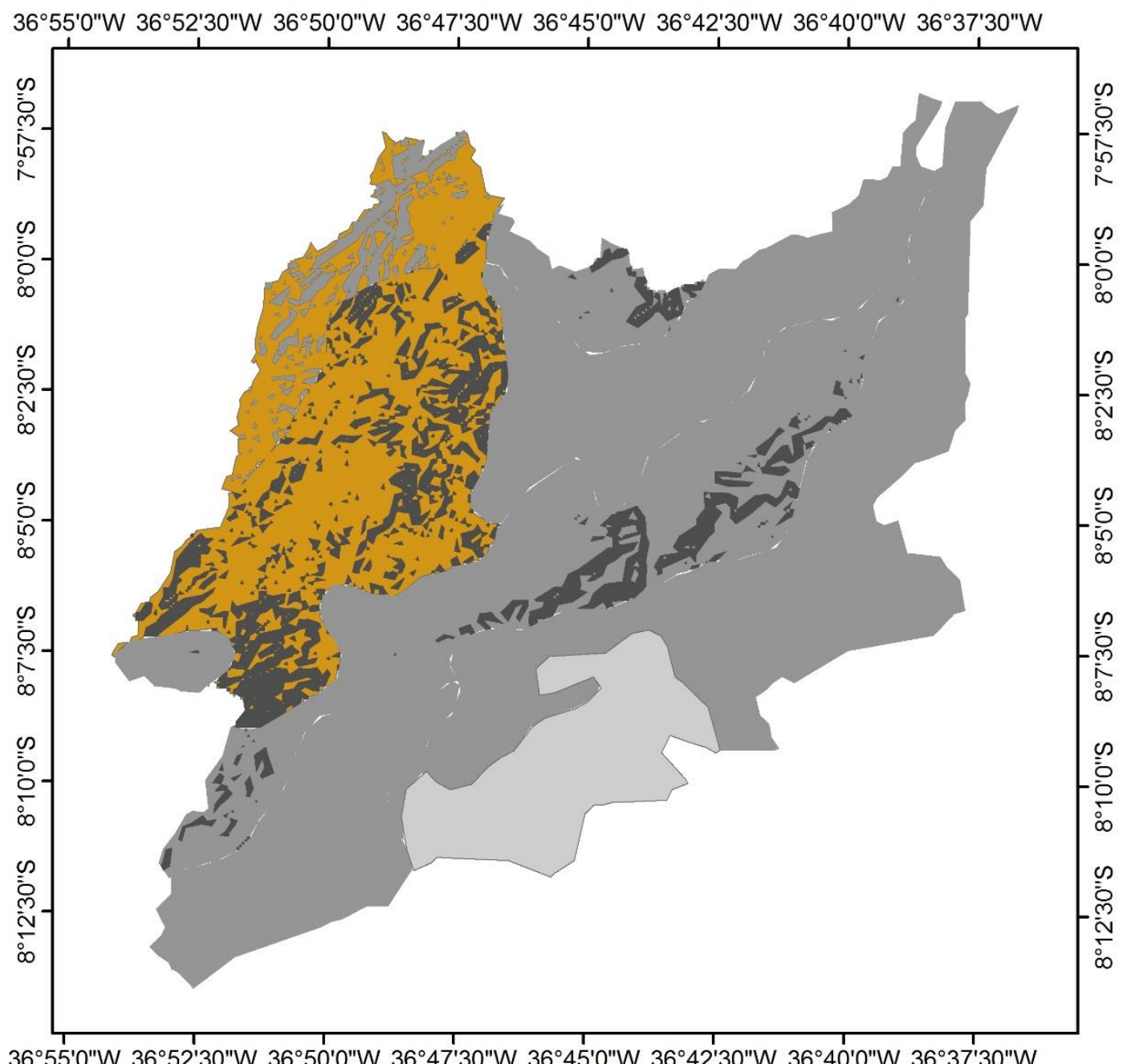

\section{Classes de Solos}
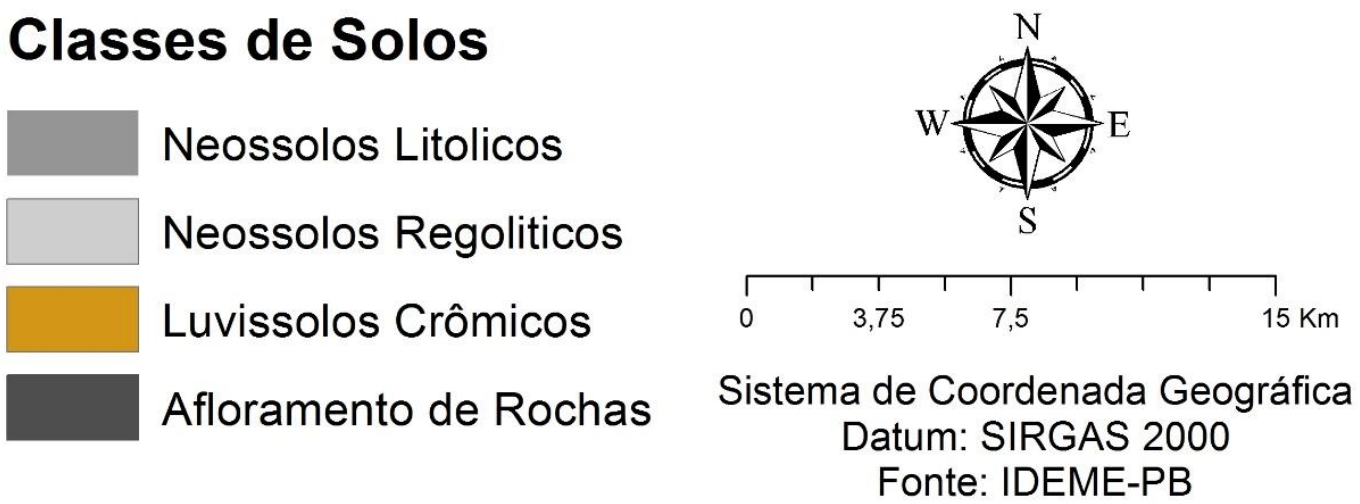

Figura 04. Mapa de Solos Detalhado da Bacia Riacho do Tigre. Stéphanie Lima,2016 
Uma tabela foi construída a partir de dados obtidos no mapeamento simples e detalhados das classes de solos, com o objetivo de comparar a quantidade de dados fornecidos pelos dois mapas. Assim como representando na Tabela 01.

\begin{tabular}{|c|c|c|}
\hline Classes de Solos & Classificação Simples & Classificação Detalhada \\
\hline Luvissolos Crômicos & $18.4 \%$ & $38 \%$ \\
\hline Neossolos Litolicos & $2.2 \%$ & $27 \%$ \\
\hline Neosssolos Regoliticos & $79.4 \%$ & $35 \%$ \\
\hline
\end{tabular}

Tabela 01. Porcentagem das associações das classes de solos detalhadas. Fonte:Stéphanie Lima, 2016

A distribuição espacial das classes de solos é interpretada, sobretudo a partir do relevo predominante na área, de acordo com as determinadas características de classe ou tipo de solos, recorrentes dos processos naturais de sua formação. Os maciços residuais cristalinos e fragmentos de planaltos sedimentares a superfícies rebaixadas que compõe a paisagem do semiárido justificam uma complexa distribuição de classes de solos. No Nordeste, mas especificamente na região do semiárido, em decorrência da azonalidade que marca esta porção do território, a formação de classes de solos ocorre em função do controle litológico.

Os mantos de intemperismo do Nordeste semiárido são pouco espessos e resultam do saldo de um balanço denudacional, que favorece a erosão sobre os agentes pedogenéticos (SOUZA et. al 2014). Sendo importante compreender as condições ambientais iniciais que levaram a formação dos mantos de intemperismo na região do Nordeste. Na escala histórica de observação, os conjuntos pedológicos da região podem ser tomados como "constantes", ou seja, os fatores exógenos responsáveis pela pedogênese seriam estáveis, ou apresentariam pouca oscilação dos seus parâmetros de operação. Assim podem-se identificar duas categorias de catenas, a saber, catenas com pedimentos e "catenas com inselbergs e pedimentos", ambas sem a presença de relictos importantes de intemperismo prévio (Gerrard, 1995). No entanto, oscilações de grande escala normalmente produzem ciclicidade na distribuição dos sistemas morfológicos, como potenciais sequencias de solos, geneticamente diferenciadas, associadas a posições topográficas distintas (cimeiras regionais x pedimentos) ( SOUZA et. al 2014).

As unidades de mapeamento NC57 e NC25 são constituídos nas catenas em pedimentos, que são ocorrentes nas áreas de maciços residuais, em locais que não são comuns. A unidades de 
mapeamento Re39, Re66 e Re32, REe13 e Re58 se formam nas catenas com inselberg e pedimentos, pois é comum que desenvolva-se em terrenos cristalinos e granitóides, com ângulos de encosta em parte controlados pela superfície basal de intemperismo. As encostas se apresentam como pedimentos íngremes, com até 10 graus de inclinação (BARROS et al.)

Contudo, a falta de dados sobre algumas das classes e suas unidades de mapeamento, na fonte de dados a qual foi utilizada, criou-se uma falha no trabalho e não permitiu um conhecimento pedológico completo da bacia. Entretanto há objetivos futuros de completar e aprofundar-se em dados completos sobre a Bacia Riacho do Tigre.

\section{CONSIDERAÇÕES FINAIS}

Nesta análise feita a partir de dados de relevo foi de contribuir com o conhecimento pedológico para analises de características físico-naturais de uma área, especificamente dos tipos de solos existentes e sua relação com a paisagem e com o relevo. Apresentando possíveis técnicas de refinamento para um maior detalhamento de mapas pedológicos.

A abordagem deste trabalho é sobretudo ressaltar a contribuição que os dados morfométricos podem oferecer ao mapeamento digital de solos para que seja possível uma caracterização pedológica e geoambiental detalhada de uma região. Além da sua importância política e social, uma vez que o solo se tratando de um recurso natural essencial para a agricultura e ou produção de alimentos, é necessário que seja compreendido de sua forma ampla e complexa, a fim de construir um planejamento de manejo e uso adequado, com limites estabelecidos de exploração.

\section{REFERÊNCIAS}

CARVALHO, C.C.N. Mapa digital de solos: Uma proposta metodológica usando inferência fuzzy. Revista Brasileira de Engenharia Agrícola 1996 ten Caten et al. Ciência Rural, v.42, n.11, nov, 2012. e Ambiental, v.13, n.1, p.46-55, 2009.

CHAGAS, C. S; FERNANDES FILHO, E. I; Rocha, M. F; JUNIOR, W. C; NETO, N. C. S. N. Avaliação de modelos digitais de elevação para aplicação em um mapeamento digital de solos. Revista Brasileira de Engenharia Agricola e Ambiental, v. 14, n. 2, p. 218-226, 2010.

CHAGAS, C. da S. Atributos topográficos e dados do Landsat7 no mapeamento digital de solos com uso de redes neurais. Pesquisa Agropecuária Brasileira, v.45, n.5, p.497-507, 2010. 
CHAGAS, C. S.; CARVALHO JÚNIOR, W. ; BHERING, S. B. . Integração de Dados do QuickBird e Atributos do Terreno no Mapeamento Digital de Solos por Redes Neurais Artificiais. Revista Brasileira de Ciência do Solo (Impresso), v. 35, p. 693-704, 2011.

CPRM. Companhia de Pesquisa de Recursos Minerais. Projeto Cadastro de Fontes de Abastecimento por Água Subterrânea: Diagnóstico do Município de São João do Tigre. Recife: $\quad 2005 . \quad$ DPRM/PRODEEM, em: <http://webserver1.cprm.gov.br/rehi/atlas/paraiba/relatorios/SAOJ180.pdf.> Acesso em 29 de fevereiro de 2016 .

GUERRA, T. J. A.; JORGE, O. C. M.; Degradação dos Solos do Brasil. 1ª Ed. Cap 4- págs 129136. Rio de Janeiro. Bertrand Brasil. 2014

LEPSCH, Igo F. 19 lições de pedologia. São Paulo: Oficina de textos, 2011.

PINHEIRO, H. S. K. ; CHAGAS, C. S. ; CARVALHO JÚNIOR, W. ; ANJOS, L. H. . Modelos de elevação para obtenção de atributos topográficos utilizados em mapeamento digital de solos. Pesquisa Agropecuária Brasileira (Online), v. 47, p. 1384-1394, 2012.

RIVELENTI, R. C. ; Coelho, Ricardo Marques ; ADAMI, Samuel Fernando ; Oliveira, Stanley Robson de Medeiros . Mineração de dados para inferência de relações solo-paisagem em mapeamentos digitais de solo. Pesquisa Agropecuária Brasileira (Online), v. 44, p. 1-9, 2009.

SANTOS. H. G.; MENDONÇA-SANTOS, M.L. Mapeamento digital de classes e atributos de solos: métodos, paradigmas e novas técnicas. - Rio de Janeiro : Embrapa Solos, 2003

PEDOLOGIA FÁCIL . Disponivel em:< http://www.pedologiafacil.com.br/enquetes/enq56.php> Acesso em 10 de junho de 2016

Recebido em: 14/08/2016

Aceito para publicação em: 01/10/2016 